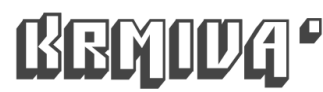

\section{UTJECAJ PRIMJENE KRUTOG STAJSKOG GNOJA NA PRINOS KRME POLU- PRIRODNOG TRAVNJAKA}

\author{
THE EFFECT OF FARM YARD MANURE APPLICATION ON THE FORAGE \\ YIELD OF SEMI-NATURAL GRASSLAND
}

Marina Vranić, K. Bošnjak, R. Gantner, Matea Županović, Anja Novak, Ana Trubelja, Ines Lisjak, K. Krapinec

Izvorni znanstveni članak - Original scientific paper

Primljeno - Received: 16. prosinac - December 2020

\section{SAŽETAK}

Cilj istraživanja bio je utvrditi prinos suhe tvari (ST) krme poluprirodnog travnjaka nakon jedne godine i nakon deset godina proljetne i jesenske primjene krutog stajskog gnoja (KSG) u količini od $30 \mathrm{t} \mathrm{ha}^{-1}$ te isto usporediti s rezultatima klasične mineralne gnojidbe.

Za potrebe ovog istraživanja provedena su četiri gnojidbena tretmana: (i) $30 \mathrm{t} \mathrm{ha}^{-1} \mathrm{KSG}-\mathrm{a}$ svako proljeće (tretman A); $30 \mathrm{t} \mathrm{ha}^{-1} \mathrm{KSG}^{-a}$ svaku jesen (tretman B); (iii) 0 t/ha KSG-a + NPK i KAN svako proljeće (tretman C); (iv) $0 \mathrm{t} / \mathrm{ha} \mathrm{KSG-a}+$ NPK i KAN svaku jesen (tretman D).

$\mathrm{U}$ dvogodišnjem prosjeku utvrđen je ukupan prosječan viši prinos ST krme $(P<0,05)$ tretmana $B\left(8,28\right.$ tha $\left.^{-1}\right)$ u usporedbi s tretmanom $A\left(7,63\right.$ tha $\left.^{-1}\right)(P<0,05)$. Unutar tretmana A, B i D nije bilo značajnih razlika po godinama istraživanja. Gnojidba mineralnim gnojivima u proljeće (tretman C) i u jesen (tretman (D) rezultirala je većim prinosom ST u usporedbi s gnojidbom KSG-om $(P<0,05)$. Vrijeme primjene mineralnih gnojiva (proljeće-jesen) nije utjecalo na prinos $S T(P>0,05)$. Zaključeno je da je efikasnija gnojidba poluprirodnog travnjaka s $30 \mathrm{t} \mathrm{KSG} \mathrm{ha-1} \mathrm{u}$ jesen nego u proljeće jer je rezultirala višim prinosom ST krme poluprirodnog travnjaka. Primjena mineralnih gnojiva se pokazala superiornijom u odnosu na gnojidbu s 30 t KSG/ha-1 u proljeće ili u jesen.

Ključne riječi: poluprirodni travnjak, kruti stajski gnoj, gnojidba, prinos suhe tvari

\section{UVOD}

Travnjačke površine u ukupnim poljoprivrednim površinama $\mathrm{RH}$ predstavljaju značajan krmni resurs. Prema podacima Statističkog ljetopisa (DZS, 2018.) trajni travnjaci (prirodni i poluprirodni travnjaci) su u 2017. godini zauzimali 607.555 ha, odnosno 40,59 \% ukupne korištene poljoprivredne površine u RH.

Poluprirodni travnjaci su uglavnom niske produktivnosti koja se može povećati primjenom nekih agrotehničkih zahvata poput gnojidbe (Štybnarova i sur., 2014.).

Prof. dr. sc. Marina Vranić, izv. prof. dr. sc. Krešimir Bošnjak, e-mail: kbosnjak@agr.hr, Agronomski fakultet Sveučilišta u Zagrebu, Zavod za specijalnu proizvodnju bilja, Svetošimunska cesta 25, Zagreb, Hrvatska;

Izv. prof. dr. sc. Ranko Gantner, Fakultet agrobiotehničkih znanosti Osijek, Sveučilište Josipa Jurja Strossmayera u Osijeku, Vladimira Preloga 1, Osijek, Hrvatska;

Matea Županović, Anja Novak, Ana Trubelja, Ines Lisjak, studentice na Agronomskom fakultetu Sveučilišta u Zagrebu, Svetošimunska cesta 25, Zagreb, Hrvatska;

Prof. dr. sc. Krešimir Krapinec, Šumarski fakultet Sveučilište u Zagrebu, Zavod za zaštitu šuma i lovno gospodarenje, Svetošimunska 25, Zagreb, Hrvatska 
Na travnjacima se mogu primjenjivati organska i mineralna gnojiva. Organska gnojiva su prirodni materijali biljnog (zelena gnojidba, biljni ostatci, kućanski otpad, kompost) ili životinjskog porijekla (kruti stajski gnoj, gnojovka ili polutekuće stajsko gnojivo i gnojnica ili tekuće stajsko gnojivo) (Kisić, 2014.). Organska gnojiva sadrže dosta organske tvari (OT) i malu koncentraciju mikro i makro hranjiva, dok mineralna gnojiva imaju veću koncentraciju osnovnih hranjiva i ne sadrže organske spojeve (Gašpar, 1996.). Hranjiva iz organskih gnojiva su biljkama dostupna nakon mikrobiološkog procesa mineralizacije organskih sastojaka (Bašić i Herceg, 2010.). Stoga, organska gnojiva otpuštaju hranjiva kroz duži period i dugoročno poboljšavaju kemijske, fizikalne i mikrobiološke osobine tla (Zheng i sur., 2010.; Wang, 2014.).

Kruti stajski gnoj (KSG) je smjesa stelje, krutih i tekućih životinjskih izlučevina različitog stupnja biološke razgrađenosti, stabilnosti i zrelosti (MAFF, 1982.). Dobiva se stajskim držanjem domaćih životinja na stelji, a njegova kvaliteta i upotrebna vrijednost ovise o vrsti stoke, vrsti i količini stelje, hranidbi, načinu skladištenja i manipulacije te uvjetima i razini dozrijevanja (Bašić i Herceg, 2010.).

Mineralna gnojiva su soli, dobivene kemijskom obradom ili sintezom prirodnih sirovina, koje u svojem sastavu imaju biogene elemente u većoj koncentraciji od bilo kojeg organskog gnojiva (Bašić i Herceg, 2010.). Primjena mineralnih gnojiva je efikasnija od primjene organskih gnojiva jer izravno osiguravaju hranjiva za biljke i mikroorganizme tla (Gašpar, 1996.), ali se za njihovu proizvodnju koristi puno fosilne energije i lako se gube iz tla ispiranjem nitrata (FAO, 2017.).

U usporedbi s dušičnim mineralnim gnojivima, čija je iskoristivost oko $60 \%$ u ratarskim usjevima (Jayasundara i sur., 2007.), iskoristivost $\mathrm{N}$ iz organskih gnojiva varira od 60 do $90 \%$ (MAFF, 1982.). Odabir vrste gnojiva ovisi o očekivanom utjecaju gnojidbe na prinos i kvalitetu krme te troškovima nabave i primjene. Primjena organskih gnojiva povezana je s većim troškovima prijevoza i distribucije po travnjaku, a primjena mineralnih gnojiva s većim troškovima nabave.

Radi nekih od prednosti korištenja organskih gnojiva u usporedbi s mineralnim gnojivima, poput povećanja sadržaja organske tvari u tlu, povećanja vodnog i vodozračnog kapaciteta tla (Zheng i sur.,
2010.; Wang, 2014.; FAO, 2017.) te promicanja održivosti poljoprivrednih ekosustava (Zheng i sur., 2010.), organska gnojiva se preporuča koristiti u održivim sustavima poljoprivredne proizvodnje (Ulen, 1993.), posebno u ekološkom uzgoju (Lamkin, 1990.).

Prema rezultatima ranijih istraživanja, gnojidba brdsko planinskih poluprirodnih travnjaka KSG-om može povećati prinos suhe tvari (ST) travnjaka za 0.5-2.5 t ha-1 što je izraženije u sušnim godinama proizvodnje (Julianna i sur., 2013.). Prinos ST travnjaka može se povećati sa oko $2,5 \mathrm{t} \mathrm{ha}^{-1}$ na oko $6.0 \mathrm{t} \mathrm{ha}^{-1} \mathrm{~s}$ primjenom $60 \mathrm{t} \mathrm{KSG} /$ ha $^{-1}$ godišnje (Dijk i sur., 1990.). Crofts i Jefferson (1994.) navode da se za intenzivnu proizvodnju krme preporuča primijeniti maksimalno 12,5 t KSG/ha-1 godišnje, a Sinclair i sur. (2013.) navodi da se na travnjacima može promijeniti max 50 t KSG/ha-1 godišnje. Osim povećanja prinosa ST, gnojidba travnjaka povećava ukupnu hranidbenu vrijednost krme (Malgeryd, 1994.; McCartney i sur., 2004.), koja predstavlja koncentraciju hranjivih tvari po jedinici ST i količinu krme koju životinja može konzumirati (Vranić i sur., 2004., 2017.; Knežević i sur., 2009.).

Zbog mogućih varijacija sastava KSG, u usporedbi s mineralnim gnojivima, teže je optimizirati gnojidbu travnjaka s obzirom na vrijeme, frekvenciju i primijenjenu količinu (Thomas i Xiying, 2017.; Kim i sur., 2014.). Osim toga, utjecaj primjene KSG-a na prinos i kvalitetu krme ovisi o fitocenološkim, klimatskim i pedološkim uvjetima, pa je potrebno provoditi vlastita istraživanja.

Hipoteza istraživanja bila je da gnojidba KSG i mineralnim gnojivima različito utječu na prinos ST krme poluprirodnog travnjaka. Cilj istraživanja bio je utvrditi prinos ST krme poluprirodnog travnjaka nakon jedne godine i nakon deset godina proljetne

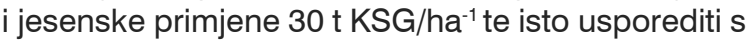
rezultatima klasične mineralne gnojidbe.

\section{MATERIJALI I METODE RADA}

\section{Lokacija istraživanja}

Istraživanje je provedeno na pokusnim površinama pokušališta Sveučilišta u Zagrebu Agronomskog fakulteta Centra za travnjaštvo smještenog na $638 \mathrm{~m}$ nadmorske visine u Parku prirode Medvednica. Za provedbu istraživanja korištena je pokusna površina od 192 m². 


\section{Klimatski podaci}

Podaci o količini oborina i srednjim mjesečnim temperaturama tijekom vegetacijske sezone 2004. i 2014. godine s mjerne stanice Medvednica - Puntijarka prikazani su u Tablici 1. i 2. (DHMZ, 2004., 2014.)

Iz tablice 1 je vidljivo da je tijekom vegetacijske sezone 2014. palo više oborina (ukupno $1159,1 \mathrm{~mm}$, odnosno prosječno po mjesecu 165,6 mm) u odnosu na vegetacijsku sezonu 2004. godine (ukupno 850,5 mm, odnosno prosječno po mjesecu 121,5 mm). U 2004. godini mjesec s najviše oborina bio je listopad, dok je u 2014. to bio rujan. Najmanje oborina je tijekom vegetacijske sezone 2004. godine palo u rujnu, a 2014. u travnju.

Iz tablice 2 je vidljivo da je vegetacijska sezona 2014. bila toplija za $0,37^{\circ} \mathrm{C}$ (prosječno po mjesecu $11,97{ }^{\circ} \mathrm{C}$ ) u odnosu na vegetacijsku sezonu 2004. godine (prosječno po mjesecu $11,6^{\circ} \mathrm{C}$ ). Tijekom vegetacijske sezone 2004. i 2014. godine najtopliji mjesec bio je srpanj, a najhladniji travanj.

\section{Gnojidbeni tretmani}

$\mathrm{Na}$ poluprirodnom travnjaku zajednice Arhenatheretum medioeuropaeum ruderale provedeno je istraživanje utjecaja gnojidbenih tretmana na prinos ST krme u razdoblju od deset godina (2004. 2014.). Pokus je postavljen 2013. godine po slučajnom blok rasporedu s deset gnojidbenih tretmana.
Za potrebe ovog istraživanja izdvojeni su rezultati četiriju tretmana gnojidbe za 2004. i 2014. godinu: (i) $30 \mathrm{t} \mathrm{ha}^{-1} \mathrm{KSG}-\mathrm{a}$ svako proljeće (tretman A); $30 \mathrm{t} \mathrm{ha}^{-1} \mathrm{KSG}-\mathrm{a}$ svaku jesen (tretman B); (iii) $0 \mathrm{t} / \mathrm{ha}$ KSG-a + NPK i KAN svako proljeće (tretman C); (iv) $0 \mathrm{t} / \mathrm{ha}$ KSG-a + NPK i KAN svaku jesen (tretman D). Gnojidbeni tretmani su provedeni u 4 ponavljanja raspoređenih po slučajnom blok rasporedu. Osnovne pokusne parcelice imale su površinu $12 \mathrm{~m}^{2}(6 \mathrm{~m} \times 2 \mathrm{~m})$, a razmak među parcelicama bio je $2 \mathrm{~m}$.

KSG je na pokusne parcelice ručno i ravnomjerno raspoređen grabljama. Organska gnojidba bazirana na 30 t KSG ha ${ }^{-1}$ je iznosila 36 kg KSG parcela-1.

Mineralna gnojidba bazirana na 500 kg NPK (8:26:26) ha-1 je iznosila 0,6 kg NPK parcela-1. Mineralna gnojidba bazirana na 600 kg KAN-a ha-1 je iznosila 0,72 kg KAN-a parcela-1.

Botanički sastav je utvrđen ručnim razdvajanjem $200 \mathrm{~g}$ svježe biljne mase 2004. godine sa svake pokusne parcele (ukupno je razdvojeno 16 uzoraka). Uzorci za utvrđivanje botaničkog sastava tratine uzeti su neposredno nakon košnje i vaganja biljne mase radi utvrđivanje prinosa ST. Uzorci biljne mase su razdvojeni na trave, mahunarke i korove, a njihova je zastupljenost u tratini izražena u postotku. Utvrđeno je da se tratina 2004. godine sastojala od $73,65 \%$ trava, $0,47 \%$ mahunarki i 25,88 \% korova.

Tablica 1. Srednja mjesečna količina oborina u mm za 2004. i 2014., Medvednica - Puntijarka (DHMZ, 2004., 2014.) Table 1 Mean monthly precipitation in mm for 2004 and 2014, Medvednica - Puntijarka

\begin{tabular}{||c|c|c|c|c|c|c|c|c|c||}
\hline $\begin{array}{c}\text { Godina } \\
\text { Year }\end{array}$ & $\begin{array}{c}\text { Travanj } \\
\text { April }\end{array}$ & $\begin{array}{c}\text { Svibanj } \\
\text { May }\end{array}$ & $\begin{array}{c}\text { Lipanj } \\
\text { June }\end{array}$ & $\begin{array}{c}\text { Srpanj } \\
\text { July }\end{array}$ & $\begin{array}{c}\text { Kolovoz } \\
\text { August }\end{array}$ & $\begin{array}{c}\text { Rujan } \\
\text { September }\end{array}$ & $\begin{array}{c}\text { Listopad } \\
\text { October }\end{array}$ & $\begin{array}{c}\text { Ukupno } \\
\text { Total }\end{array}$ & $\begin{array}{c}\text { Prosjek } \\
\text { Mean }\end{array}$ \\
\hline 2004. & 161,3 & 88,9 & 129,3 & 103 & 93,9 & 72,7 & 201,4 & 850,5 & 121,5 \\
\hline 2014. & 112,1 & 134,4 & 179,7 & 179,9 & 149,3 & 252 & 151,7 & 1159,1 & 165,6 \\
\hline
\end{tabular}

Tablica 2. Srednje mjesečne temperature za vegetacijsku sezonu 2004. i 2014. godine (Medvednica - Puntijarka, $\left.\mathbf{u}^{\circ} \mathrm{C}\right)$

Table 2 Mean monthly temperatures for vegetation season 2004 and 2014 (Medvednica - Puntijarka, in ${ }^{\circ} \mathrm{C}$ )

\begin{tabular}{||c|c|c|c|c|c|c|c|c||}
\hline $\begin{array}{c}\text { Godina } \\
\text { Year }\end{array}$ & $\begin{array}{c}\text { Travanj } \\
\text { April }\end{array}$ & $\begin{array}{c}\text { Svibanj } \\
\text { May }\end{array}$ & $\begin{array}{c}\text { Lipanj } \\
\text { June }\end{array}$ & $\begin{array}{c}\text { Srpanj } \\
\text { July }\end{array}$ & $\begin{array}{c}\text { Kolovoz } \\
\text { August }\end{array}$ & $\begin{array}{c}\text { Rujan } \\
\text { September }\end{array}$ & $\begin{array}{c}\text { Listopad } \\
\text { October }\end{array}$ & $\begin{array}{c}\text { Prosjek } \\
\text { Average }\end{array}$ \\
\hline 2004. & 6,1 & 9 & 13,6 & 15,7 & 16,1 & 11,3 & 9,7 & 11,6 \\
\hline 2014. & 7,8 & 9,8 & 14,6 & 16,2 & 14,8 & 11,4 & 9,2 & 11,97 \\
\hline
\end{tabular}


Samohodnom grebenastom kosilicom pokošene su pokusne parcele 2004. i 2014. godine. Košnja je obavljena u početku metličanja dominantnih trava na visini od $5 \mathrm{~cm}$ od tla. Tijekom vegetacijske sezone skinuta su po 4 otkosa krme. Za svaku godinu istraživanja su prikazani rezultati ukupnog prinosa ST ha-1 po tretmanu istraživanja.

Tratina je pokošena po sredini svake pokusne parcele. Kosilicom je zahvaćena traka (zahvat kosilice) širine 1,2 m kako bi se izbjegao rubni utjecaj parcele na prinos krme. Pokošena biljna masa je sakupljena na šatorska krila, vagana visećom digitalnom vagom radi utvrđivanja prinosa zelene mase. Uzorak zelene biljne mase (oko $500 \mathrm{~g}$ ) je sušen na temperaturi od $60^{\circ} \mathrm{C}$ do konstantne mase radi utvrđivanja sadržaja ST-i i izračuna prinosa ST-i po jedinici površine.

Kemijski sastav KSG-a primijenjenog 2004. i 2014. prikazan je u Tablici 3.

Gnojidba mineralnim gnojivima sadržavala je ukupno $202 \mathrm{~kg} \mathrm{~N} \mathrm{ha}^{-1}, 130 \mathrm{~kg} \mathrm{P}_{2} \mathrm{O}_{5} \mathrm{ha}^{-1}, 130 \mathrm{~kg} \mathrm{~K}_{2} \mathrm{O}$ ha $^{-1}$ obje godine. Primijenjena količina N, P i K hra- njiva gnojidbom KSG-om iznosila je 177, 59 i 81 kg $\mathrm{ha}^{-1}$ tim redom 2004. godine, a 2014. godine 295, 13 i $20 \mathrm{~kg} \mathrm{ha}^{-1}$ tim redom.

U Tablici 3. vidljive su varijacije ukupno primijenjenih količina pojedinih hranjiva putem KSG. Koncentracija hranjiva u KSG je varijabilna i ovisna o brojnim čimbenicima poput vrste stoke, vrste i količine stelje, hranidbe, načina skladištenja i manipulacije s gnojem te uvjetima i razini dozrijevanja (Bašić i Herceg, 2010.). Međutim, i tijekom godine se koncentracija hranjiva u KSG može značajno mijenjati što zahtijeva provedbu kemijskih analiza KSG prije primjene radi optimizacije potrebne količine (Thomas i Xiying, 2017.; Kim i sur., 2014.).

$U$ jesen 9. godine istraživanja, sondom su uzeti uzorci tla na svakoj pokusnoj parcelici i na površini pored pokusne parcele koja nije gnojena (kontrola) radi utvrđivanja utjecaja gnojidbe na kemijski sastav tla (Tablica 4.).

Primjena KSG-a je povećala pH vrijednost i sadržaj humusa u tlu u odnosu na gnojidbu mineralnim gnojivima i kontrolni tretman (Tablica 4.).

Tablica 3. Kemijski sastav primijenjenog krutog stajskog gnoja po godinama istraživanja (\% u suhoj tvari) Table 3 farm yard manure chemical composition (\% in dry matter)

\begin{tabular}{||l|c|c|c|c|c|c|c|c||}
\hline \multicolumn{1}{|c|}{ god./yr. } & $\mathrm{pH}$ & $\mathrm{ST} / \mathrm{DM}$ & $\mathrm{C}$ org. & $\mathrm{OT} / \mathrm{OM}$ & $\mathrm{N}$ & $\mathrm{NH}_{3}-\mathrm{N}$ & $\mathrm{P}_{2} \mathrm{O}_{5}$ & $\mathrm{~K}_{2} \mathrm{O}$ \\
\hline 2004. & 7,9 & 40 & 40 & 75 & 2,2 & 0,07 & 0,59 & 0,88 \\
\hline 2014. & 8,2 & 21 & 43 & 67 & 2,8 & 0,15 & 1,80 & 1,36 \\
\hline
\end{tabular}

god., godina; $\mathrm{ST}$, suha tvar; $\mathrm{C}$, ugljik; OT, organska tvar; $\mathrm{N}$, dušik; $\mathrm{NH}_{3}-\mathrm{N}$, ammonium $\mathrm{N} ; \mathrm{P}_{2} \mathrm{O}_{5}$, fosfor pentoksid; $\mathrm{K}_{2} \mathrm{O}$, kalijev oksid;

yr., year; DM, dry matter; C, carbon; OM, organic matter; $\mathrm{N}$, nitrogen; $\mathrm{NH}_{3}-\mathrm{N}$, ammonium nitrogen; $\mathrm{P}_{2} \mathrm{O}_{5}$, phosphorus pentoxide; $\mathrm{K}_{2} \mathrm{O}$, potassium oxide.

Tablica 4. Utjecaj gnojidbe na kemijski sastav tla

Table 4 The effect of fertilizing tretment on soil chemical composition

\begin{tabular}{|c|c|c|c|c|c|}
\hline \multirow{2}{*}{$\begin{array}{l}\text { Kemijski parametar / } \\
\text { Chemical parameter }\end{array}$} & \multicolumn{5}{|c|}{ Gnojidbeni tretman/Fertilising treatment } \\
\hline & A & B & C & $\mathrm{D}$ & $\mathrm{E}$ \\
\hline $\mathrm{pH} \mathrm{H} \mathrm{H}_{2} \mathrm{O}$ & 5,94 & 5,94 & 5,4 & 5,2 & 5,6 \\
\hline $\mathrm{pH} \mathrm{KCl}$ & 4,78 & 4,83 & 4,2 & 4,0 & 4,6 \\
\hline$\%$ humus & 5,46 & 5,24 & 5,07 & 4,26 & 4,72 \\
\hline $\mathrm{N}(\mathrm{mg} / 100 \mathrm{~g})$ & 0,39 & 0,37 & 0,51 & 0,44 & 0,48 \\
\hline $\mathrm{P}_{2} \mathrm{O}_{5}(\mathrm{mg} / 100 \mathrm{~g})$ & 5,1 & 7,0 & 8,23 & 10,2 & 3,4 \\
\hline $\mathrm{K}_{2} \mathrm{O}(\mathrm{mg} / 100 \mathrm{~g})$ & 17,0 & 22,5 & 14,5 & 14,5 & 29,5 \\
\hline
\end{tabular}

A, 30 t ha-1 KSG-a svako proljeće; B, 30 t ha ${ }^{-1}$ KSG-a svaku jesen; C, 0 t ha- ${ }^{-1}$ KSG-a + NPK i KAN svako proljeće; D, 0 t ha- ${ }^{-1}$ KSG-a + NPK i KAN svaku jesen; $\mathrm{E}, 0$ t gnojiva ha-1; $\mathrm{N}$, dušik; $\mathrm{P}_{2} \mathrm{O}_{5}$, fosfor pentoksid; $\mathrm{K}_{2} \mathrm{O}$, kalijev oksid;

$\mathrm{A}, 30 \mathrm{t}$ ha ${ }^{-1}$ of FYM every spring; $\mathrm{B}, 30 \mathrm{t} \mathrm{ha}^{-1}$ of FYM very fall; $\mathrm{C}, 0 \mathrm{t}$ ha ${ }^{-1} \mathrm{FYM}+\mathrm{NPK}$ and KAN every spring; $\mathrm{D}, 0 \mathrm{t}$ ha ${ }^{-1} \mathrm{FYM}+\mathrm{NPK}$ and KAN every fall; $\mathrm{E}, 0 \mathrm{t}$ fertilizer ha-1 $\mathrm{N}$, nitrogen; $\mathrm{P}_{2} \mathrm{O}_{5}$, phosphorus pentoxide; $\mathrm{K}_{2} \mathrm{O}$, potassium oxide. 
Sadržaj kalijevih soli je bio viši kod gnojidbe KSGom tijekom 9 godina u odnosu na primjenu mineralnih gnojiva, a niži u odnosu na kontrolni tretman.

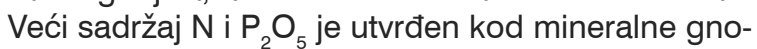
jidbe.

\section{Kemijske analize}

Kemijski sastav primijenjenog KSG i kemijski sastav uzoraka tla je utvrđen u laboratoriju Zavoda za ishranu bilja Sveučilišta u Zagrebu Agronomskog fakulteta.

\section{Statistička obrada rezultata istraživanja}

Rezultati su obrađeni u statističkom programu SAS (SAS Institut, 1997.) koristeći MIXED proceduru.

\section{REZULTATI I RASPRAVA REZULTATA ISTRAŽIVANJA}

Za hranidbu domaćih životinja treba osigurati dovoljnu količinu krme što se izražava kao prinos ST po jedinici površine (ha). Sadržaj ST je usko povezan s energetskom vrijednošću krme jer sadrži sva organska hranjiva potencijalno dostupna životinjama (Vranić i sur., 2004.).

U Tablici 5. je prikazan prosječan prinos ST krme poluprirodnog travnjaka po gnojidbenim tretmanima nakon 1. i nakon 10-e godine istraživanja.

Unutar godina istraživanja utvrđena je tendencija većeg prinosa ST krme poluprirodnog travnja- ka tretmana B u odnosu na tretman A, a prosječno za obje godine istraživanja viši prinos $S T$ tretmana $B$ u odnosu na tretman $A(P<0,05)$ (Tablica 5.) što ukazuje na prednost jesenske primjene KSG u odnosu na proljetnu primjenu.

Prednosti primjene KSG u jesen, utvrđene ovim istraživanjem, mogu se povezati s osiguranjem hranjiva biljkama prije zimskog mirovanja vegetacije (Peel, 1938.) te potrebnom mikrobiološkom procesu mineralizacije organskih sastojaka iz KSG prije aktivnog porasta biljke u proljeće kada su joj hranjiva najpotrebnija (Wilson i sur., 2009.; Bašić i Herceg, 2010.). U suprotnosti s utvrđenim rezultatima, u nekim ranijim istraživanjima se navodi najpovoljnije vrijeme za primjenu KSG rano u proljeće prije početka vegetacije što može biti efikasnije u odnosu na jesensku ili zimsku gnojidbu (Wilson i sur., 2009.; Lamkin, 1990.; Smith, 1991.).

Proljetnom primjenom KSG, prevenira se gubitak $\mathrm{N}$ ispiranjem tijekom zime (Smith i Unwin, 1983.) ali se, s druge strane, dosta $N$ može izgubiti isparavanjem amonijaka iz KSG tijekom ožujka i travnja (Lamkin, 1990.). Ispiranje $\mathrm{N}$ tijekom zime je manje ako se na travnjaku $u$ jesen primjenjuje KSG dobiven držanjem životinja na slami (Chambers, 1994.). Primjena KSG u proljeće može rezultirati kontaminacijom krme česticama gnojiva, pa ga treba primijeniti što ranije (veljača, ožujak) (Smith, 1991.; Lamkin, 1990.).

Tablica 5. Prosječan prinos suhe tvari krme poluprirodnog travnjaka

Table 5 Average dry matter yield of semi-natural grassland

\begin{tabular}{|c|c|c|c|c|}
\hline \multirow{3}{*}{$\begin{array}{l}\text { Gnojidbeni tretmani } \\
\text { Fertilizing treatments }\end{array}$} & \multicolumn{3}{|c|}{ Prinos ST t ha-1 /DM yield (t ha-1) } & \multirow{3}{*}{$\begin{array}{l}\text { Prosječan prinos ST } \\
\text { Average DM yield }\end{array}$} \\
\hline & \multicolumn{2}{|c|}{ Godina istraživanja/Investigation year } & \multirow{2}{*}{$P$} & \\
\hline & 2004. & 2014. & & \\
\hline A & $7,50^{c}$ & $7,76^{c}$ & N.S. & $7,63^{c}$ \\
\hline B & $8,29^{c}$ & $8,27^{c}$ & N.S. & $8,28^{b}$ \\
\hline C & $11,85^{\mathrm{a}}$ & $8,81^{\mathrm{b}}$ & *** & $10,33^{a}$ \\
\hline D & $10,36^{\mathrm{b}}$ & $9,72^{\mathrm{a}}$ & N.S. & $10,04^{a}$ \\
\hline$P$ & * & ** & - & * \\
\hline SEM & 0,59 & 0,59 & - & 0,34 \\
\hline
\end{tabular}

A, 30 t ha $^{-1}$ KSG-a svako proljeće; B, 30 t ha- ${ }^{-1}$ KSG-a svaku jesen; C, 0 t ha- ${ }^{-1}$ KSG-a + NPK i KAN svako proljeće; D, 0 t ha-1 KSG-a + NPK i KAN svaku jesen SEM, standardna greška srednje vrijednosti; P, stupanj signifikantnosti. Vrijednosti u istom stupcu označene različitim slovima statistički značajno se razlikuju ( $\left.\mathrm{P}<0,05 ;{ }^{* *} \mathrm{P}<0,01\right)$. Vrijednosti $u$ istom retku se statistički značajno razlikuju ako je $\mathrm{P}$ označen $\mathrm{s}{ }^{* * *}(\mathrm{P}<0,001)$.

$A, 30 t^{\text {ha }}{ }^{-1}$ of FYM every spring; $B, 30 t$ ha ${ }^{-1}$ of FYM very fall; C, 0 t ha ${ }^{-1}$ FYM + NPK and KAN every spring; D, 0 t ha ${ }^{-1}$ FYM + NPK and KAN every fall; SEM standard error of the mean; $P$, degree of significance. Values in the same column marked in different letters differ significantly $\left({ }^{\star} P<0.05 ;{ }^{\star \star} P<0,01\right)$. Values in the same row are statistically significant if $P$ is marked with *** $(P<0,001)$. 
U ovom istraživanju je utvrđen veći prinos ST krme poluprirodnog travnjaka $(7,5$ do

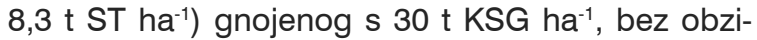
ra na vrijeme primjene (tretman $A$ i tretman $B$ ) $u$ odnosu na prinos ST krme poluprirodnog travnjaka od $6 \mathrm{t} \mathrm{ha}^{-1}$ nakon primjene $60 \mathrm{t} \mathrm{KSG}$ ha $^{-1}$ tijekom 11 godina (Dijk i sur., 1990.). Međutim, količina primijenjenog gnojiva bi trebala zadovoljiti potrebe biljaka na hranjivima, a ovisna je o stanju usjeva, plodnosti tla te klimatskim uvjetima i potencijalnom prinosu biljne mase (Butorac, 1999.; Mesić i sur., 2008.; Kisić, 2014.). Primijenjena količina KSG u ovom istraživanju se uklapa u preporučenu

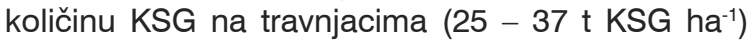
(Peel, 1938.) ili 20-30 $\mathrm{t} \mathrm{ha}^{-1}$ (Simpson i Jefferson, 1996.), manja od $50 \mathrm{t} \mathrm{ha}^{-1}$ godišnje (Sinclair i sur., 2013.), a veća od 20 t KSG ha-1 svakih tri do pet godina u cilju očuvanja bioraznolikosti (Crofts i Jefferson, 1994.).

Kod gnojidbe travnjaka mineralnim gnojivima (tretman $C$ i tretman $D$ ) utvrđen je veći prinos ST krme ha-1 $^{-1}(\mathrm{P}<0,05)$ u odnosu na gnojidbu KSG-om (tretman A i tretman B) (Tablica 4.) što je u skladu $\mathrm{S}$ ranijim istraživanjima u kojima je navedeno da mineralna gnojiva imaju veću koncentraciju osnovnih hranjiva (Gašpar, 1996.), te izravno osiguravaju hranjiva za biljke i mikroorganizme tla (FAO, 2017.).

Kod tretmana mineralne gnojidbe je nakon prve godine istraživanja utvrđen veći prinos ST tretmana $C$ u odnosu na tretman $D(P<5)$, a nakon druge godine istraživanja tretmana $D$ u odnosu na tretman C (P<0,01) (Tablica 4). U prosjeku, (2004. i 2014. godina) između proljetne i jesenske primjene mineralnih gnojiva nisu utvrđene statistički značajne razlike u prinosu ST $(P>0,05)$.

$U$ ranijim istraživanjima je preporučeno gnojiti mineralnim gnojivima u proljeće (Kisić, 2014.; FAO, 2017.) što je u suglasju s većim prinosom ST biljne mase nakon prve godine istraživanja u odnosu na jesensku gnojidbu mineralnim gnojivima $(P<0,05)$. Također, navodi se pozitivan utjecaj gnojidbe KSGom na prinos krme poluprirodnog travnjaka osobito u sušnim godinama (Julianna i sur., 2013.) što ovim istraživanjem nije potvrđeno. Tijekom vegetacijske sezone 2014. utvrđeno je više oborina u odnosu na vegetacijsku sezonu 2014. (Tablica 2.) što nije utjecalo na prinos ST krme primijenjenih gnojidbenih tretmana KSG $(P>0,05)$ (Tablica 5.).
Radi određenih prednosti korištenja organskih gnojiva u usporedbi s mineralnim gnojivima te promicanja održivosti poljoprivrednih ekosustava (Zheng i sur., 2010.), organska gnojiva se preporuča koristiti u sustavima poljoprivredne proizvodnje (Ulen, 1993.), posebno u ekološkom uzgoju (Lamkin, 1990.). Visoki je potencijal primjene KSG u gnojidbi travnjaka, ali nedovoljno iskorišten resurs u RH (Knežević i sur., 2007.). Svaka farma proizvodi stajski gnoj kao posljedicu držanja životinja, a travnjak je idealno mjesto za primjenu, i zbrinjavanje stajskog gnoja čime dolazi do recikliranja hranjiva i minimalnog nedostatka hranjiva u tlu (Knežević i sur., 2007.).

\section{ZAKLJUČAK}

$U$ ovom istraživanju se efikasnijom pokazala gnojidba KSG-om s 30 t ha-1 $^{-1}$ u jesen nego u proljeće jer je rezultirala višim prinosom suhe tvari krme poluprirodnog travnjaka. Primjena mineralnih gnojiva se pokazala superiornijom u odnosu na gnojidbu s 30 t KSG ha-1 u proljeće ili u jesen.

\section{LITERATURA}

1. Bašić, F., Herceg, N. (2010.); Temelji uzgoja bilja, Synopsis, Zagreb.

2. Butorac, A. (1999.): Opća agronomija. Školska knjiga, Zagreb.

3. Chambers, B. (1994.): Profit from better manure use. In: Living with manures, ADAS Farmer Conference, 21 June 1994, Park House Hotel, Shifnal, ADAS Conference Papers.

4. Crofts, A., Jefferson, R.G. (1994.): The Lowland Grassland Management Handbook. Peterborough: English Nature /The Royal Society for Nature Conservation (The Wildlife Trusts).

5. DHMZ (2004., 2014.): Državni hidrometeorološki Zavod, Zagreb.

6. Dijk, T.A., Postmus, J., Prins, W.H. (1990.): Long-term application of farmyard manure on grassland: effects on herbage yield and distribution of $\mathrm{N}$ and $\mathrm{P}$ in the soil profile. Conference paper : Soil-grassland-animal relationships. Proceedings of 13th general meeting of the European Grassland Federation, Banská Bystrica, Czechoslovakia, June 25-29.

7. DZS (Državni Zavod za statistiku) (2018.): Statistički ljetopis Republike Hrvatske. Državni zavod za statistiku Republike Hrvatske: 588 str. 
8. FAO (Food and Agriculture Organization) (2017.): Livestock Solutions for Climate Change. http://www. fao.org/3/a-i8098e.pdf, Accessed date: 9 February 2019.

9. Gašpar, I. (1996.): Mineralna gnojiva i gnojidba bilja, INA Petrokemija d.o.o., Kutina.

10. Jayasundara, S., Wagner-Riddle, C., Parkin, G., von Bertoldi, Peter, Warland, J., Kay, B., Voroney, P. (2007.): Minimizing nitrogen losses from a cornsoybean-winter wheat rotation with best management practices. Nutrients Cycling in Agroecosystems 79:141-159.

11. Julianna, T., Pál, P., Gábor, T. (2013.): First results of farmyard manure on hilly grassland. Animal Welfare, Ethology and Housing Systems,9, 1: 61-75.

12. Kim, D.G., Rafique, R., Leahy, P., Cochrane, M., Kiely, G. (2014.): Estimating the impact of changing fertilizer application rate, land use, and climate on nitrous oxide emissions in Irish grasslands. Plant Soil 374: 55-71.

13. Kisić, I. (2014.): Uvod u ekološku poljoprivredu. Sveučilište u Zagrebu Agronomski fakultet.

14. Knežević, M., Vranić, M., Perčulija, G., Kutnjak, H., Matić, I., Teskera, M. (2009.): Effect of the maturity stage of grass at harvesting on the chemical composition of grass clover silage. Mljekarstvo, 59, 1: 49-55.

15. Lamkin, N. (1990.): Management of manures, slurry and organic residues. In Organic Farming, pp. 86124. Organic Farming Books; Ipswich.

16. MAFF (Ministry of Agriculture, Fisheries and Food) (1982.): Profitable Utilisation of Livestock Manure. MAFF Booklet 2081. HMSO; London, 159-164.

17. Malgeryd, J. (1994.): Manure characterization. International Agrophysics, 8: 93 - 101.

18. McCartney, D.H., Bittman, S., Nuttall, W.F., (2004.): The influence of harvest management and fertilizer application on seasonal yield, crude protein concentration and $\mathrm{N}$ offtake of grasses in northeast Saskatchewan. Canadian Journal of Plant Science, 84, 1: 205-212.

19. Mesić, H., Bakšić, D., Bašić, F., Čidić, A., Durn, G., Husnjak, S., Kisić, I., Klaić, D., Komesarović, B., Mesić, M., Miko, S., Mileusnić, M., Nakić, Z., Pernar, N., Pilaš, I., Romić, D., Vrbek, B., Zgorelec, Ž. (2008.): Program trajnog motrenja tala Hrvatske, Projekt, Izrada programa trajnog motrenja tala Hrvatske s pilot projektom, Life Third Countries, LIFE05 TCY/ CRO/000105, Agencija za zaštitu okoliša, Zagreb, str. 131.

20. Peel, W.R. (1938.): Grassland Management for the practical Farmer. London: Macmillian and Co. pp 135-140.
21. SAS Institute (1997.): SAS/STAT software. Changes and enhancements trough release 6.12. SAS Inst., Cary,NC.

22. Simpson, N.A., Jefferson, R.G. (1996.): Use of faryard manure on semi-natural (meadow) grassland. English Nature Research Reports No. 150 English Nature.

23. Sinclair, A., Litterick, A., Crooks, B., Chambers, B. (2013.): Optimising the application of bulky organic fertilisers. (C)RUC (Scotland's Rural College) 2013, West Mains Road, Edinburgh EH9 3JG. SRUC is a charity registered in Scotland, No. SC003712.

24. Smith, K.A., Unwin, R.J. (1983.): Fertiliser value of organic manures in the UK. The Fertiliser Society Proceedings, No.221, London, The Fertiliser Society.

25. Štybnarova, M., Mićova, P., Fijala, K., Karabcova, H., Latal, O., Pozdišek, J. (2014.): Effect of organic fertilizers on botanical composition of grassland, herbage yield and quality, Agrowyzkum Rapotin Ltd., Vyzkumniku 267, 78813 Vikyrovice, Czesh Republic.

26. Thomas, B.W., Xiying, H. (2017.): Nitrous oxide emitted from soil receiving anaerobically digested solid cattle manure. Journal of Environmental Quality, 46: 741-750.

27. Ulen, B. (1993.): Losses of nutrients through leaching and surface runoff from manure-containing composts. Biological Agriculture and Horticulture, 10: 29-37.

28. Vranić, M., Knežević, M., Perčulija, G., Leto, J., Bošnjak, K., Rupić, I. (2004.): Kvaliteta voluminozne krme na obiteljskim poljoprivrednim gospodarstvima u Republici Hrvatskoj. Kvaliteta travne silaže na obiteljskim poljoprivrednim gospodarstvima. Mljekarstvo. 54 (3) 165-174.

29. Vranić, M., Bošnjak, K., Leto, J., Lukšić, B., Glavanović, S. (2017.): Procjena prinosa suhe tvari krme poluprirodnog travnjaka NIR spektroskopijom. Stočarstvo : časopis za unapređenje stočarstva. 70, 1: 3-12.

30. Wang, J. (2014.): Decentralized biogas technology of anaerobic digestion and farm ecosystem: opportunities and challenges. Front. Energy Resources 2.

31. Zheng, Y.H., Li, Z.F., Feng, S.F., Lucas, M., Wu, G.L., $\mathrm{Li}, \mathrm{Y}$. (2010.): Biomass energy utilization in rural areas may contribute to alleviating energy crisis and global warming: a case study in a typical agro-village of Shandong, China. Renew. Sustainable Energy Review, 14, 3132-3139.

32. Wilson, C., Undi, M., Tenuta, M., Wittenberg, K.M., Flaten, D., Krause, D.O., Entz, M.H., Holley, R., Ominski, K.H. (2009.): Pasture productivity, cattle productivity and metabolic status following fertilization of a grassland with liquid hog manure: A three - year study, University of Manitoba, Winnipeg, Manitoba, Canada R3T 2N2. 


\section{SUMMARY}

The objective of the study was to determine the yield of forage dry matter (DM) of a semi-natural lawn after one year and after ten years of spring and autumn application of farm yrd manure (FYM) in the amount of $30 \mathrm{t} \mathrm{ha}^{-1}$ and to compare the same with the results of standard mineral fertilization.

Four fertilizing treatments with fertilizer application were investigated: (i) $30 \mathrm{t} \mathrm{ha}^{-1}$ of FYM every spring (treatment $\mathrm{A}$ ); $30 \mathrm{t} \mathrm{ha}^{-1}$ of FYM every fall (treatment B); (iii) $0 \mathrm{t} \mathrm{ha}^{-1}$ of FYM + NPK and KAN every spring (treatment $\mathrm{C}$ ); (iv) $0 \mathrm{t} \mathrm{ha}^{-1}$ of FYM + NPK and KAN every autumn (treatment D).

The total average higher DM forage yield $(P<0.05)$ of treatment $B$ (8.28 $\left.\mathrm{t} \mathrm{ha}^{-1}\right)$ compared to treatment $A\left(7.63 \mathrm{t} \mathrm{ha}^{-1}\right)$ was determined. Statistically significant differences in DM yield after the first year of the study or after the 10th year of the study were found between A and B fertilizing treatments. Fertilization with mineral fertilizers in the spring (treatment $C$ ) and in the autumn (treatment D) resulted in a higher DM yield compared to FYM treatments. It was concluded that, in terms of DM yield, the fertilization of semi-natural lawn with $30 \mathrm{t}^{\text {of }} \mathrm{FYM} \mathrm{ha}^{-1}$ is more efficient in autumn than in spring. The application of mineral fertilizers was found superior to fertilization with $30 \mathrm{t}$ of $\mathrm{FYM} \mathrm{ha}^{-1}$ in spring or autumn.

Key words: semi-natural lawn, farm yrd manure, dry matter yield 